\title{
Successful endoscopic removal of a fully covered self-expandable metallic stent that fractured above a benign distal bile duct stricture
}

A 45-year-old man underwent placement of a 10 -mm-diameter, fully covered, self-expandable metallic stent (FCSEMS; 6-cm-long Bonastent M-intraductal; Medico's Hirata, Tokyo, Japan) across the major duodenal papilla to treat a bile duct stricture associated with chronic pancreatitis ( $\triangleright$ Fig.1a). Four months later, he was admitted to our hospital for removal of the FCSEMS. However, abdominal X-ray and duodenoscopy revealed that the stent had fractured in the mid-portion and the inferior end was located above the distal bile duct stricture

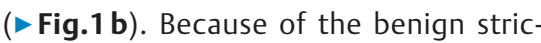
ture, it was necessary to retrieve the stent remnants. We attempted to achieve this by several methods, using grasping forceps or balloon catheters, but encountered great difficulty when the fractured stent became stuck in the stricture. After several attempts, we were able to grasp the bottom edge of the fractured stent using biopsy forceps (Radial Jaw 4P; Boston Scientific, Boston, Massachusetts, USA) and remove it through the distal bile duct stricture without any complications by gentle pushing of the endoscope (in the same way as a lithotripsy: twisting the endoscope clockwise while advancing it to the anal side of the duodenum) ( Fig.2). Finally, we succeeded in extracting the stent using a snare through the scope.

FCSEMS are primarily used to treat malignant strictures, but recently they have been coming into use to treat benign strictures [1]. Stent fracture is a rare complication of FCSEMS, and there are few reports about FCSEMS fracturing above benign distal bile duct strictures [2, 3]. In the present case, residual stenosis made it very difficult to grasp the FCSEMS and remove it through the stenosis.

No standard methods have yet been established for removal of fractured FCSEMS. Therefore, a variety of devices should be used as appropriate for each individual case.
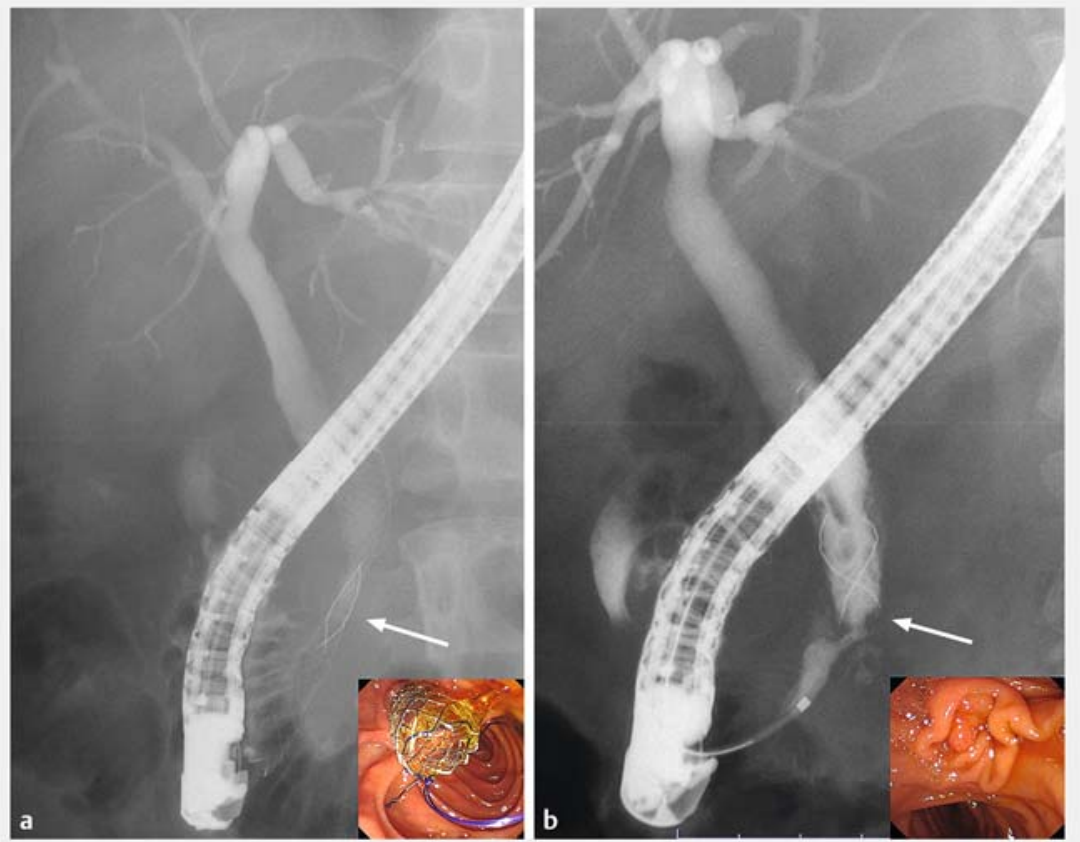

- Fig. 1 a A 10-mm-diameter, fully covered, self-expandable metallic stent (FCSEMS) placed across the major duodenal papilla in a 45-year-old man. $\mathbf{b}$ The FCSEMS fractured in the midportion with the inferior end of the stent located above the distal bile duct stricture.
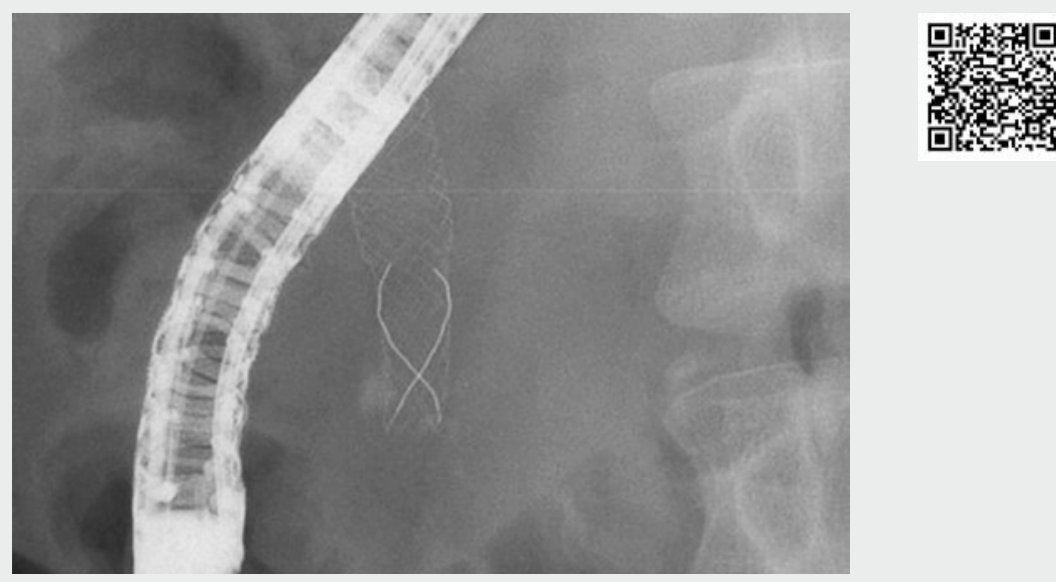

Video 1 The bottom edge of the fractured FCSEMS was successfully grasped using biopsy forceps and removed through the distal bile duct stricture by gentle pushing of the endoscope. 

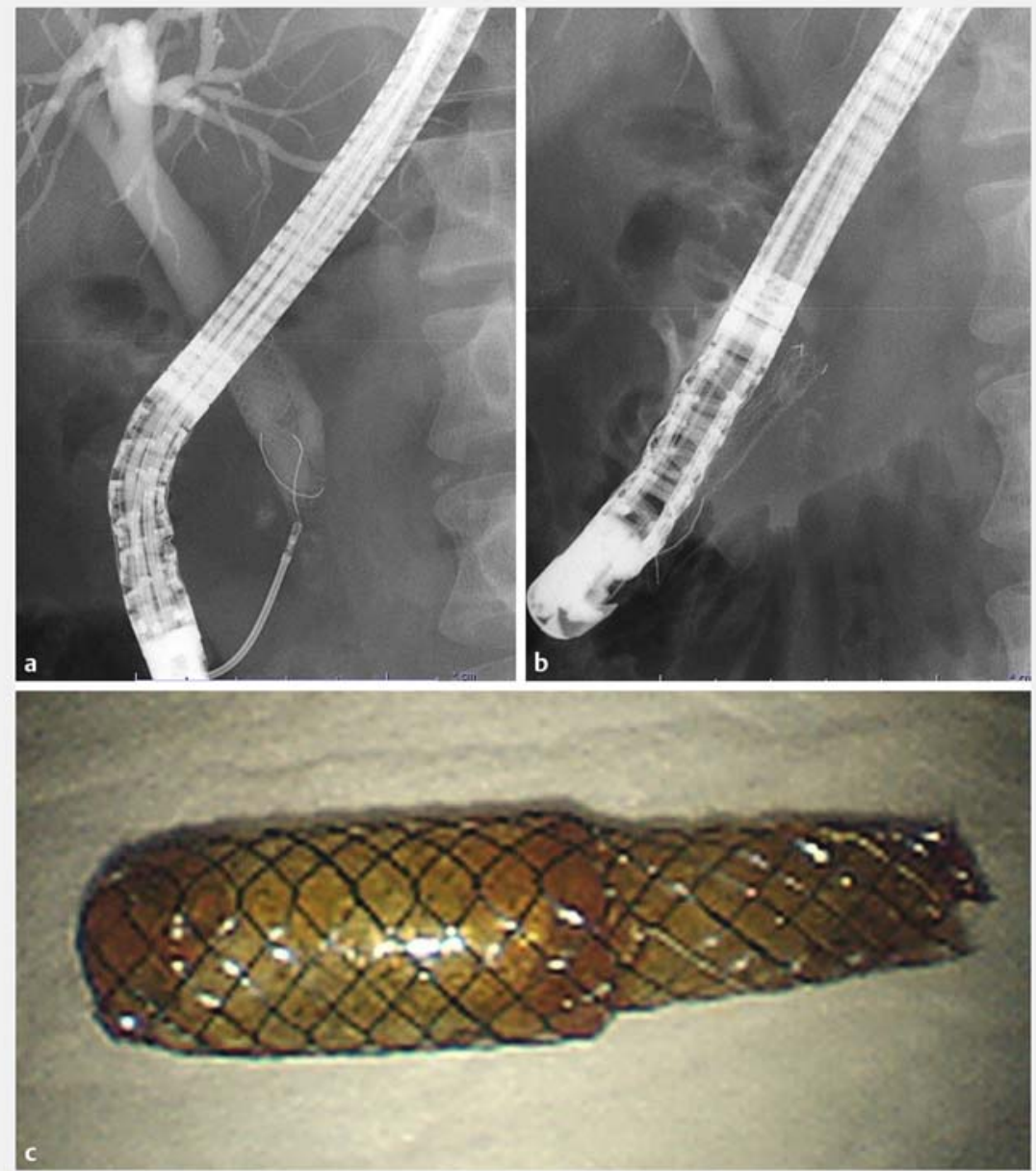

Fig. 2 a, b We were able to grasp the bottom edge of the fractured FCSEMS using biopsy forceps and remove it through the distal bile duct stricture by gentle pushing of the endoscope. c The fractured FCSEMS.

Endoscopy_UCTN_Code_CPL_1AK_2AD

\section{Competing interests}

The authors declare that they have no conflict of interest.

The authors

\section{Masatoshi Murakami, Nao Fujimori, Yuta} Suehiro, Tomonobu Hioki, Kazuhide Matsumoto, Takamasa Oono, Yoshihiro Ogawa

Department of Medicine and Bioregulatory Science, Graduate School of Medical Sciences, Kyushu University, Fukuoka, Japan

\section{Corresponding author}

\section{Nao Fujimori, MD, PhD}

Department of Medicine and Bioregulatory Science, Graduate School of Medical

Sciences, Kyushu University, 3-1-1 Maidashi, Higashi-ku, Fukuoka 812-8582, Japan

fujimori@intmed3.med.kyushu-u.ac.jp

\section{References}

[1] Siiki A, Helminen M, Sand J et al. Covered self-expanding metal stents may be preferable to plastic stents in the treatment of chronic pancreatitis-related biliary strictures: a systematic review comparing 2 methods of stent therapy in benign biliary strictures. J Clin Gastroenterol 2014; 48 : 635-643

[2] Alkhiari R, Patel V, Cohen L. Spontaneous fracture of a covered self-expandable biliary metal stent and endoscopic technique for removal. Can J Gastroenterol hepatol 2014; 28: 411-412

[3] Joo KR, Paik CN, Chung WC et al. Fracture of Self-Expandable Metal Stent during Endoscopic Removal in Benign Biliary Stricture. Clin Endosc 2013; 46: 95-97

\section{Bibliography}

Endoscopy 2021; 53: E11-E12

DOI 10.1055/a-1167-7861

ISSN 0013-726X

published online 19.5.2020

(c) 2020. Thieme. All rights reserved.

Georg Thieme Verlag KG, Rüdigerstraße 14, 70469 Stuttgart, Germany

\section{ENDOSCOPY E-VIDEOS}

https://eref.thieme.de/e-videos

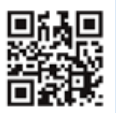

Endoscopy E-Videos is a free access online section, reporting on interesting cases and new techniques in gastroenterological endoscopy. All papers include a high quality video and all contributions are freely accessible online.

This section has its own submission website at

https://mc.manuscriptcentral.com/e-videos 